Systematic Review

\title{
The Relevance of the OPRM1 118A>G Genetic Variant for Opioid Requirement in Pain Treatment: A Meta-Analysis
}

Xueying Zhang, MA ${ }^{1}$, Yongxin Liang, PhD², Nannan Zhang, MA², Ying Yan, MA ${ }^{1}$, Shanling Liu, PhD², Hao Fengxi, MA ${ }^{1}$, Dai Zhao, MA ${ }^{1}$, and Haichen Chu, $\mathrm{PhD}^{2}$

From: ${ }^{1}$ Department of Anesthesiology, Qingdao University, Qingdao, China; ${ }^{2}$ Department of Anesthesiology, Affiliated Hospital of Qingdao University, Qingdao, China

Address Correspondence: Haichen Chu, PhD Department of Anesthesiology, Affiliated Hospital of Qingdao University 16 Jiangsu Rd.

Qingdao, China 276000 E-mail: chiefchu@163.com

Disclaimer: There was no external funding in the preparation of this manuscript.

Conflict of interest: Each author certifies that he or she, or a member of his or her immediate family, has no commercial association (i.e., consultancies, stock ownership, equity interest, patent/licensing arrangements, etc.) that might pose a conflict of interest in connection with the submitted manuscript.

Manuscript received: 08 28-2018

Revised manuscript received: 12-26-2018

Accepted for publication: 02-07-2019

Free full manuscript: www.painphysicianjournal.

com
Background: There is obvious difference in individual response to opioids. Many studies have examined the correlation between the $\mu$-opioid receptor 1 (OPRM1) 118A $>\mathrm{G}$ genetic variation and opioid requirement in pain treatment, but the conclusion remains elusive.

Objectives: To investigate whether the OPRM1 118A>G genetic variation is associated with the opioid requirement.

Study Design: Systematic review and meta-analysis.

Methods: PubMed, Cochrane library, and EMBASE databases were systematically searched up to May 5, 2018, using the keywords "OPRM1," "genetic variant," "opioid," and "pain" to identify reviews or meta-analyses on this topic. Two independent reviewers performed the data extraction and assessed study quality. The authors investigated the standardized mean difference (SMD) of opioid requirement between $A A$ homozygotes and $G$ allele carriers. The authors also examined the association between the OPRM1 118A>G genetic variation and adverse effects such as nausea and vomiting. Potential bias was assessed using the Egger's test and the Begg's test.

Results: A total of 530 articles were retrieved from the databases searched, and 36 studies involving 8,609 patients were included in the final analysis. $G$ allele carriers required a higher mean opioid dose (SMD: $0.17 ; 95 \%$ confidence interval $[C I]:[0.12,0.22] ; P<0.001)$ and displayed less nausea risk difference (RD): $-0.04 ; 95 \% \mathrm{Cl}:[-0.06,-0.01])$, but the incident rate of vomiting has no relationship with the genetic variant than AA homozygotes in a random-effects meta-analysis. Although there was no evidence of publication bias (Begg's test: $P=0.333$; Egger's: $P=0.561$ ), heterogeneity was present among studies $\left(I^{2}=54.3 \%\right)$. In the subgroup meta-analyses, there was also significance observed in the postoperative pain setting.

Limitations: In all of the articles reviewed, postoperative pain and cancer pain were mostly discussed except for one in other pain setting.

Conclusions: In this meta-analysis, the results indicate the OPRM1 A118G polymorphism was associated with the opioid requirement and the adverse effects in pain treatment especially in postoperative pain. This may provide valuable information for clinicians to adopt personalized pain management by properly using the opioids in individual patients.

Key words: OPRM1, genetic variation, opioid, pain, side effect, review, meta-analysis

Pain Physician 2019: 22:331-340
D) management is mainly relying on drug treatment. Opioids are currently the most effective analgesics used for moderate to severe pain. Morphine, fentanyl, sufentanil, and oxycodone are commonly used opioids in the clinic. However, individual differences in pain sensitivity and response make it difficult for clinicians to use opioids properly. Inappropriate use of opioids may be one 
of the main causes of side effects such as nausea, vomiting, respiratory depression, constipation, and others. Therefore, patients are either suffering from inadequate pain relief or suffering from side effects caused by drugs when the opioids are not properly used (1). Genetic factors may be an important cause of these individual differences (2-4). The $\mu$-opioid receptor 1 (OPRM1), a primary binding site for morphine, is an important target for treating pain $(5,6)$. The OPRM1 A118G genetic variation has been a major area of focus for research in the pharmacogenetics study of opioid response (7-9). Some animal or human studies show $G$ carriers had reduced analgesic response to morphine compared with the AA homozygotes $(10,11)$. However, the same correlation was not observed in other studies (12). A large number of research has been conducted to study the correlation between OPRM1 A118G genetic variation and opioid needs and the corresponding adverse effects. Therefore, it is very important to provide accurate evidence to prove the association between OPRM1 A118G genetic variation and opioid requirements in different pain settings that remains elusive. Therefore, a systematic review and meta-analysis was performed to evaluate this association.

\section{Methods}

This meta-analysis was performed according to the Cochrane Handbook for Systematic Reviews of Interventions 6 and presented based on Preferred Reporting Items for Systematic Reviews and Meta-Analyses guidelines.

\section{Search Trials}

We searched the PubMed, Cochrane library, and EMBASE databases from the inception dates to May 5, 2018, using the keywords "OPRM1," "genetic variation," "opioid," and "pain" to identify published systematic reviews or meta-analyses evaluating the association between OPRM1 A118G genetic variation and opioid requirements in different pain settings. The references of the identified original articles or review articles were also retrieved and reviewed to provide a complete and precise literature search.

\section{Study Selection and Inclusion Criteria}

Two researchers (X.Y.Z. and Y.Y.) independently assessed the articles for their eligibility for inclusion. The following criteria was used to determine the articles eligibility for inclusion, articles must be: 1) randomized or cohort studies; 2) in clinical pain settings including postoperative pain, cancer pain, or other pain; 3) containing opioid dosage requirements; and 4) containing side effects such as nausea, vomiting, and respiration depression.

\section{Data Extraction}

Two researchers (X.Y.Z. and Y.Y.) independently extracted the following information from each study: first author, year of publication, race, numbers of patients, genetic variants, whether genotype frequencies agreed with the Hardy-Weinberg equilibrium (HWE), amounts of opioids (mean \pm standard deviation [SD]), pain setting, and clinical outcome. Disagreements between the 2 researchers were resolved by consensus or consultation with a third author (F.X.H.). We determined whether the genotype frequencies agreed with HWE by calculating the $\chi 2$ goodness-of-fit. The endpoints of our meta-analysis included opioid consumption and side effects during the pain treatment. When the data format in the articles were not suitable for the analyses, we contacted the article corresponding author to get the data set. If the data included in the article were not complete and the authors could not be contacted for more information, the article was excluded for analysis. The details for identifying qualified studies and the exclusion of the studies are shown in Fig. 1. The main information extracted from the included studies are shown in Table 1.

\section{Statistical Analysis}

Data extracted from each article were processed and analyzed using RevMan 5.2 (The Nordic Cochrane Centre for The Cochrane Collaboration, Copenhagen, Denmark) and Stata SE Version 12.0 (StataCorp LP, College Station, TX) software packages. We calculated the standardized mean difference (SMD) to standardize the data of opioid consumption because this was represented in different units. We used odds ratio as the parameters of drug side effects. A random-effects model was used to pool the data, and statistical heterogeneity between summary data were evaluated using the $\mathrm{I}^{2}$ statistic. $\mathrm{I}^{2}$ ranged from 0 to $100 \%\left(\mathrm{I}^{2}>\right.$ $50 \%$ shows significant heterogeneity) (13). The results are illustrated as point estimates and $95 \%$ confidence intervals (Cls). We used the Egger's test and the Begg's test to construct plots illustrating the standardized effect and the corresponding standard errors to evaluate potential bias. 


\section{Review: the Role of OPRM1 A118G in Pain}

The $\mu$-opioid receptor gene OPRM1, a member of the G-protein-coupled receptor superfamily, is one of the genes with a high probability of relevance for pain and pain treatment. It encodes the predominant receptor of opioids, which are still the major analgesics used in pain therapy, and it was among the first pain-related genes screened for functional variants. Genetic variants of OPRM1 were found to be associated with opioid individual responses in different pain conditions including acute postoperative pain $(8,14-16)$, chronic pain $(17,18)$, and cancer-related pain $(19,20)$.

The OPRM1 118 A>G (rs1799971) genetic variation emerged as one of the most promising candidates for a genetic modulation of analgesia. The variant $G$ allele carriers of cancer patients and postoperative patients requires an increase in the doses of morphine to achieve pain control $(7,21)$. Although a meta-analysis showed $G$ allele carriers indeed need an increase in mean opioid dose than in AA homozygotes carriers, the evaluation is only performed in the postoperative pain setting (22). For the side effects of opioids and OPRM1 A118G, the correlation remains unclear. A study genotyped 165 Chinese women undergoing gynecologic surgery and showed no correlation between OPRM1 A118G with individual variation of postoperative nausea and vomiting, which are common side effects of fentanyl (23). However, some studies showed opposite results that the severity of postoperative nausea and vomiting in carriers of the variant haplotype was significantly lower than in the carriers of the other haplotypes (24).

\section{RESULts}

\section{Study Selection and Characteristics}

The details of identifying qualified studies and the exclusion criteria are shown in Fig. 1. A total of 530 articles were retrieved from PubMed, Cochrane library, and EMBASE databases, and 36 studies involving 8,609 patients were included in the final analyses. From the 530 articles, 188 articles were removed owing to duplication, with the remainder independently reviewed by 2 researchers. A total of 91 reviews were excluded. The full texts of the remaining 251 articles were reviewed and among them 215 articles were excluded for the following reasons: 154 articles were not consistent with our research topics; 34 articles were nonhuman experiments; and 27 articles did not have effective data that we needed. In the final analysis, 36 articles were included, of these, 28 articles were regarding the relationship

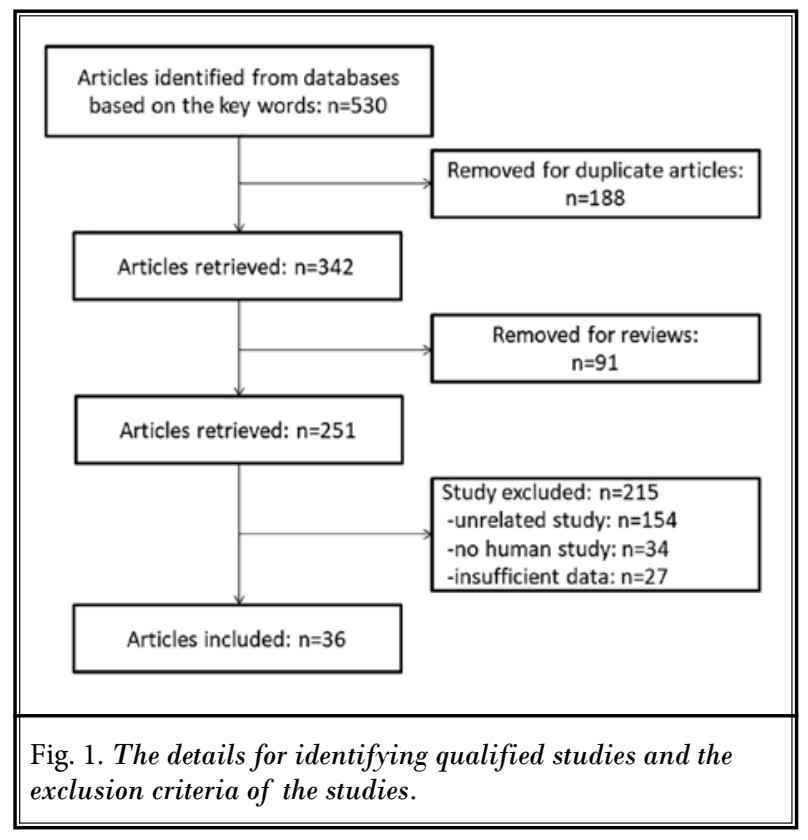

between OPRM1 and opioid demand, and 15 articles and 12 articles included were regarding the study on nausea and vomiting, respectively.

Table 1 shows the general characteristics of the 36 studies included in the final analysis. There were 8,609 patients represented in these studies, and the sample size of each study ranged from 38 to 994 . There were 4,586 AA homozygous genotypes and 4,023 G carriers including GG homozygote and AG heterozygote. Sixteen studies chose Caucasians as research subjects, 18 selected Asians, and 2 additional studies included mixed races. The countries in these studies include China (12), United States (5), Japan (3), Singapore (3), France (2), Korea (2), Germany (1), Sweden (1), Finland (1), Norway (1), Lebanon (1), Estonia (1), Czech (1), Denmark (1), and Australia (1). Thirty-one studies were in the postoperative pain setting, 4 studies were in the cancer pain setting, and one study was in another pain setting.

\section{Meta-Analysis of A118G and Opioid Intake Requirement}

Opioid consumption data including the numbers, mean dose, and SD of opioid consumption in each group, were available from 28 studies $(7,9,11,14,15,19,23,25$ 46). These studies included 3,782 homozygous $118 \mathrm{AA}$ patients and 3,245 $118 \mathrm{G}$ allele carriers. The relative SMD of the pain treatment requirement for opioids in each study is presented in a forest plot, along with the 
Pain Physician: July/August 2019: 22:331-340

Table 1. The general characteristics of the 36 studies included in the final analysis.

\begin{tabular}{|c|c|c|c|c|c|c|c|c|c|c|}
\hline NO. & Study & Country & Population & $\mathrm{N}$ & AA & G carriers & HWE & Setting & Opioid & Adverse events \\
\hline 1. & Bartosova et al (2015) (25) & Czech & Caucasian & 51 & 38 & 13 & Yes & Postoperative pain & PIR & \\
\hline 2. & Bastami et al (2014) (26) & Sweden & Caucasian & 38 & 29 & 9 & Yes & Postoperative pain & MOR & \\
\hline 3. & Boswell et al (2013) (47) & USA & Caucasian & 158 & 131 & 27 & Yes & Postoperative pain & MIX & Nausea, vomiting \\
\hline 4. & Cajanus et al (2014) (27) & Finland & Caucasian & 993 & 631 & 362 & Yes & Postoperative pain & OXC & \\
\hline 5. & Chen et al (2013) (48) & China & Asian & 129 & 56 & 73 & Yes & Postoperative pain & MOR & Nausea, vomiting \\
\hline 6. & Chou et al (2006a) (28) & China & Asian & 80 & 43 & 37 & No & Postoperative pain & MOR & Vomiting \\
\hline 7. & Chou et al (2006b) (29) & China & Asian & 120 & 74 & 46 & No & Postoperative pain & MOR & Nausea, vomiting \\
\hline 8. & Coulbault et al (2006) (29) & France & Caucasian & 74 & 57 & 17 & Yes & Postoperative pain & MOR & Nausea, vomiting \\
\hline 9. & Fukuda et al (2010) (8) & Japan & Asian & 108 & 31 & 77 & Yes & Postoperative pain & FEN & \\
\hline 10. & Gong et al (2013) (19) & China & Asian & 112 & 44 & 68 & Yes & cancer pain & MIX & \\
\hline 11. & Hajj et al (2017) (9) & Lebanon & Mixed & 89 & 69 & 20 & Yes & cancer pain & MOR & \\
\hline 12. & Hayashida et al (2008) (32) & Japan & Asian & 138 & 41 & 97 & Yes & Postoperative pain & MIX & \\
\hline 13. & Janicki et al (2006) (33) & USA & Caucasian & 101 & 70 & 31 & Yes & Postoperative pain & MOR & \\
\hline 14. & Kim et al (2013) (34) & Korea & Caucasian & 196 & 72 & 124 & Yes & Postoperative pain & FEN & \\
\hline 15. & Klepstad et al (2004) (12) & Norway & Caucasian & 99 & 78 & 21 & Yes & cancer pain & MOR & \\
\hline 16. & $\begin{array}{l}\text { Kolesnikov et al (2011) } \\
(35)\end{array}$ & Estonia & Caucasian & 102 & 82 & 20 & Yes & Postoperative pain & MOR & \\
\hline 17. & Lee et al (2016) (49) & Korea & Asian & 88 & 36 & 52 & Yes & Postoperative pain & MOR & Nausea \\
\hline 18. & Liao et al (2013) (50) & China & Asian & 97 & 42 & 55 & Yes & Postoperative pain & FEN & Nausea, vomiting \\
\hline 19. & Liu et al (2014) (51) & China & Asian & 178 & 78 & 100 & Yes & Postoperative pain & RFEN & Nausea, vomiting \\
\hline 20. & Lotsch et al (2009) (36) & Germany & Caucasian & 503 & 406 & 97 & Yes & outpatient pain & MIX & \\
\hline 21. & Mamie et al (2013) (37) & USA & Caucasian & 168 & 130 & 38 & Yes & Postoperative pain & MOR & \\
\hline 22. & Pettini et al (2018) (52) & USA & Caucasian & 63 & 45 & 18 & Yes & Postoperative pain & MOR & Nausea \\
\hline 23. & $\begin{array}{l}\text { Reyes-Gibby et al (2007) } \\
\text { (11) }\end{array}$ & USA & Caucasian & 207 & 166 & 41 & Yes & cancer pain & MOR & \\
\hline 24. & Sia et al (2008a) (38) & Singapore & Asian & 585 & 271 & 314 & Yes & Postoperative pain & MOR & Nausea, vomiting \\
\hline 25. & Sia et al (2013b) (15) & \begin{tabular}{|l} 
Singapore \\
\end{tabular} & Asian & 973 & 354 & 619 & Yes & Postoperative pain & MOR & \\
\hline 26. & Somogyi et al (2016) (39) & Australia & Mixed & 960 & 375 & 585 & Yes & Postoperative pain & MOR & Nausea \\
\hline 27. & Sugino et al (2014) (24) & Japan & Caucasian & 82 & 27 & 55 & Yes & Postoperative pain & FEN & Nausea \\
\hline 28. & Tan et al (2009) (54) & \begin{tabular}{|l|} 
Singapore \\
\end{tabular} & Asian & 994 & 389 & 605 & Yes & Postoperative pain & MOR & Vomiting \\
\hline 29. & $\begin{array}{l}\text { Thomazeau et al (2016) } \\
(40)\end{array}$ & France & Caucasian & 108 & 90 & 18 & Yes & Postoperative pain & MOR & \\
\hline 30. & Wang et al (2016) (41) & China & Asian & 120 & 46 & 74 & Yes & Postoperative pain & SFEN & \\
\hline 31. & Xu et al (2015) (42) & China & Asian & 161 & 63 & 98 & Yes & Postoperative pain & SFEN & Nausea, vomiting \\
\hline 32. & Zhang et al (2010a) (14) & China & Asian & 174 & 86 & 88 & Yes & Postoperative pain & FEN & Nausea, vomiting \\
\hline 33. & Zhang et al (2011b) (23) & China & Asian & 165 & 80 & 85 & No & Postoperative pain & FEN & Nausea, vomiting \\
\hline 34. & Zhang et al (2018) (45) & China & Asian & 240 & 102 & 138 & Yes & Postoperative pain & FEN & \\
\hline 35. & Zhang et al (2013) (44) & China & Asian & 96 & 35 & 61 & Yes & Postoperative pain & FEN & Nausea, vomiting \\
\hline 36. & Zwisler et al (2012) (46) & Denmark & Caucasian & 266 & 219 & 47 & Yes & Postoperative pain & OXC & \\
\hline
\end{tabular}

Abbreviations: PIR, Piritramide; MOR, Morphine; OXC, Oxycodone; FEN, Fentanyl; RFEN, remifentanil; SFEN, sufentanil

overall results of the meta-analysis (Fig. 2). The results showed $G$ allele carriers required a higher dose of opioids when compared with the wild-type AA homozygotes (SMD: $0.17 ; 95 \% \mathrm{Cl}$ : $[0.12,0.22]$; $P<0.001$ ). The heterogeneity was significant $(I 2=54.3 \% ; P<0.001)$.

We performed analysis in the subgroups based on the type of pain setting such as postoperative pain, cancer pain, and other pain. The results are shown in 
a forest plot, along with the overall results of the metaanalysis (Fig. 3). In the postoperative pain group, the results showed that $G$ allele carriers required a higher dose of opioids when compared with the requirement for the wildtype AA homozygotes (SMD: 0.18 ; $95 \% \mathrm{Cl}:[0.13,0.23] ; P<$ $0.001)$. The heterogeneity was not significant $\left(I^{2}=48.7 \%\right)$. In the cancer pain group, similar results were shown. The heterogeneity was also not significant $\left(I^{2}=44.7 \%\right)$.

We used the Egger's test and the Begg's test to plot the standardized effect and the corresponding standard errors to evaluate potential bias. The results showed no publication bias in these studies (Fig. 4. Begg's test: $P$ $=0.333$; Egger's: $P=0.561$ ). We also conducted the influence analysis, and the results showed that the impacts of these articles on the results were relatively stable, and the quality of the literature was relatively high (Fig. 5).

\section{Meta-Analysis of A118G and Drug Side Effects}

Data for side effects, including nausea and vomiting, were available from 16 studies $(14,23,24,29,30,38,39,42,47$ 54). They were divided into 2 groups: nausea and vomiting. The nausea group included 1,475 118AA homozygotes and 1,687 118G carriers, whereas the vomiting group included 1,361 118AA homozygotes and 1,521 $118 \mathrm{G}$ carriers. We performed the analysis in these 2 groups separately (Figs. 6 and 7). For

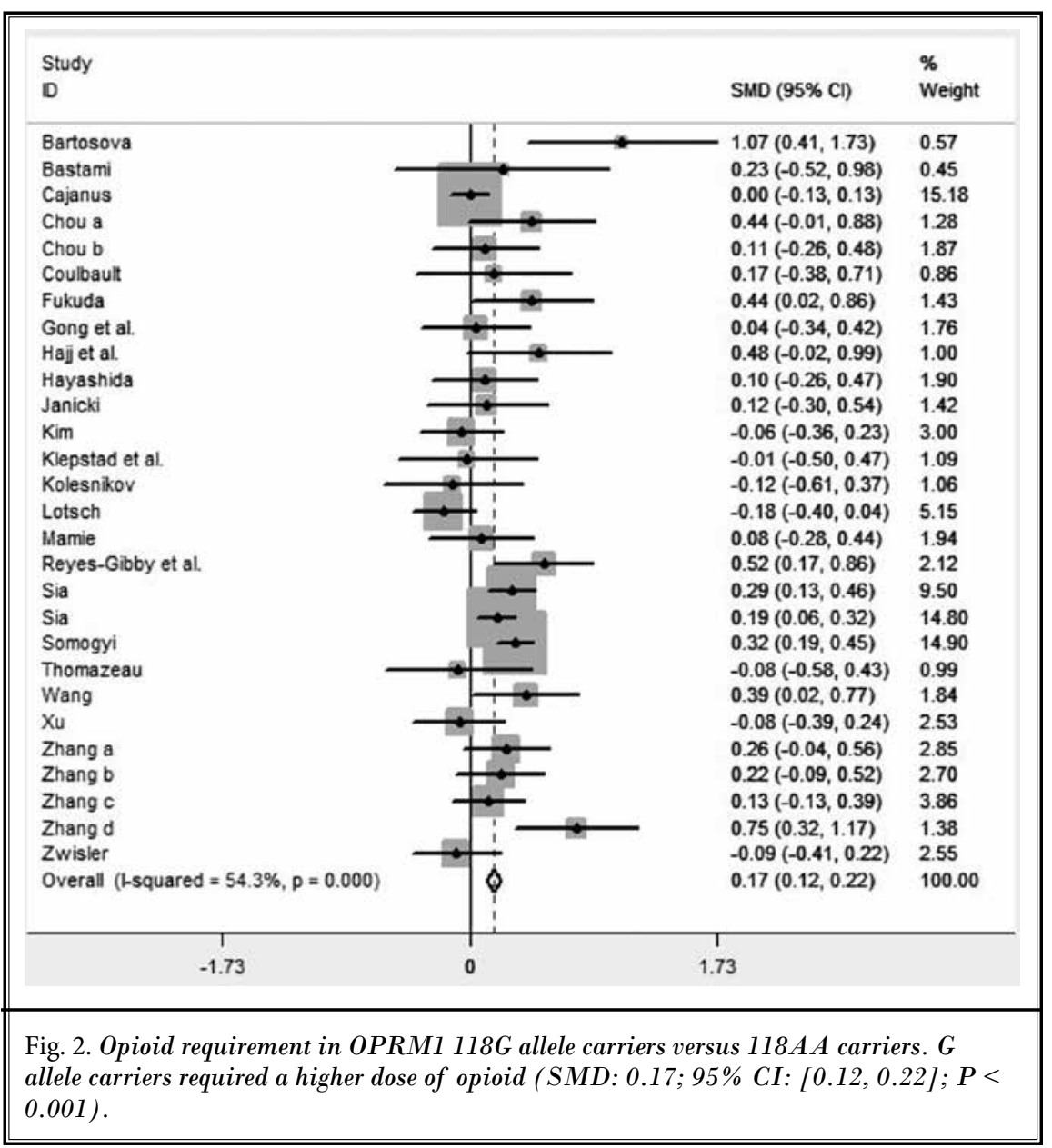

the nausea group, the results showed less nausea events in $\mathrm{G}$ carriers than in the AA homozygotes (RD: $-0.04 ; 95 \% \mathrm{Cl}$ : $[-0.06,-0.01])$, but in the vomiting group, there was no significant correlation found between the $A 118 \mathrm{G}$ and vomiting (RD: 1.29; $95 \% \mathrm{Cl}$ : $[0.99,1.69])$.

\section{Discussion}

OPRM1, ending gene for the predominant receptor of opioids, is one of the genes with a high probability of relevance for pain and pain treatment. Although there has been a meta-analysis about this scheme in 2009 (55), the meta-analysis only included 9 articles. Moreover, their results showed only weak evidence of increased opioid dosage requirements in homozygous carriers of the $\mathrm{G}$ allele. The authors did not perform a meta-analysis on the available evidence of the clinical relevance of the OPRM1 118A $>$ G polymorphism. Our meta-analysis and review included 36 articles of OPRM1 A118G and opioid requirement and side effects in pain management. The main findings of our meta-analysis showed that the OPRM1 $\mathrm{G}$ allele carriers required a higher mean opioid dose, but the events of nausea were reduced than in AA homozygotes in a random-effects meta-analysis. In another meta-analysis of genetic variation on sensitivity to opioid analgesics in 
patients with postoperative pain, the results show that the $G$ carrier is not only related to reduced nausea events but also is related to vomiting (56). This may account for the increased number of studies from our research in recent years (51), which weights $9.8 \%$ in the results from 12 articles (Fig. 7), and its results showed there was no significant association between OPRM1 A118G and nausea or vomiting.

Our meta-analysis showed that the sensitivity to opioids of $118 \mathrm{G}$ allele carriers had reduced, reflected by increased opioid consumption and reduced nausea events. This can be partially explained by related basic research studies, but for the main findings of the opioid requirement, the heterogeneity of these 28 articles remained high. To investigate the source of this heterogeneity, we carried out the subgroup analysis based on the different pain settings including postoperative pain, cancer pain, and other pain. The results show that this heterogeneity is mainly derived from the different pain settings (Fig. 3).

With the development of gene

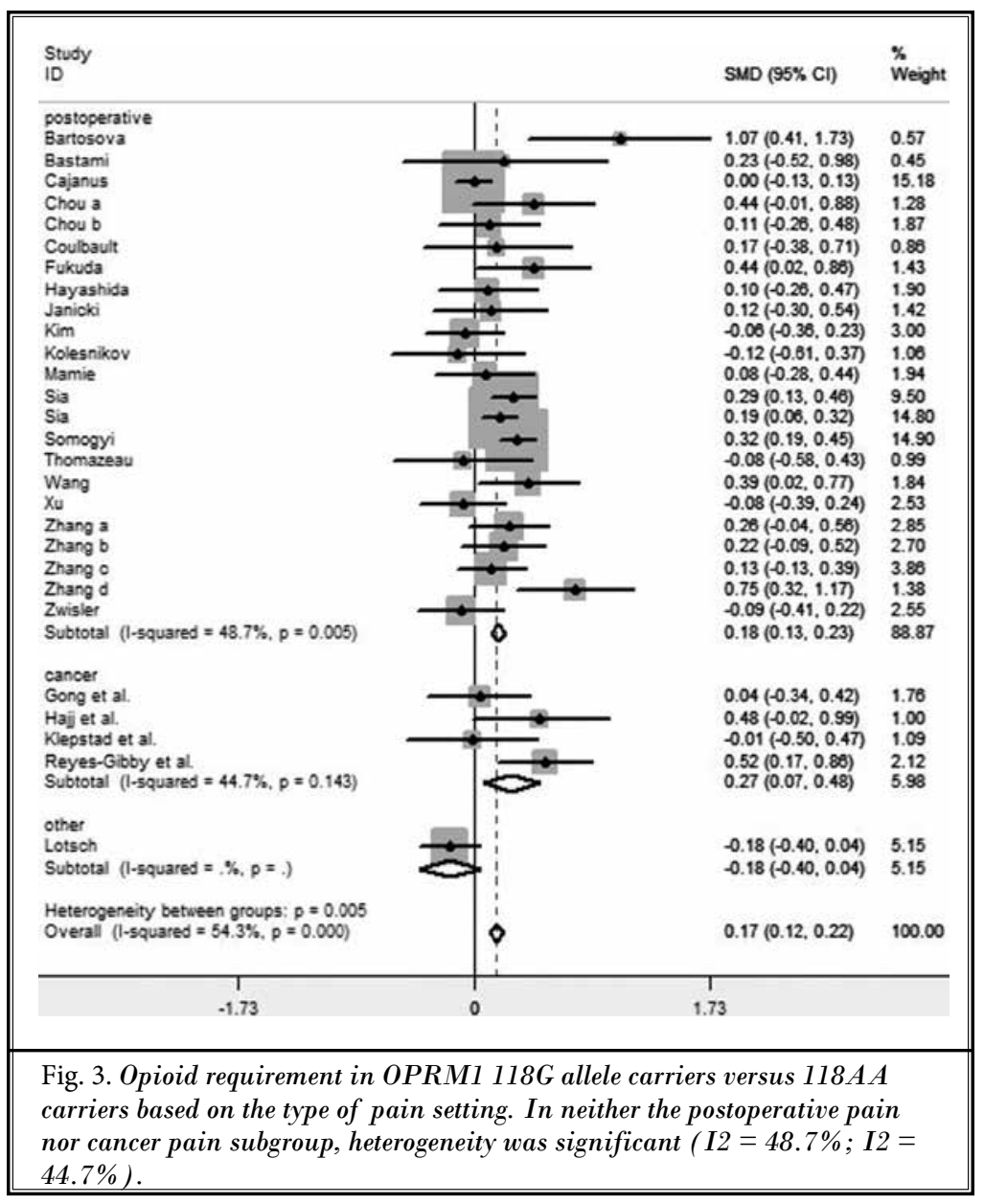

Fig. 3. Opioid requirement in OPRM1 $118 \mathrm{G}$ allele carriers versus $118 \mathrm{AA}$ arriers based on the type of pain setting. In neither the postoperative pain $44.7 \%)$.
Fig. 4. The results showed no publication bias in these studies.

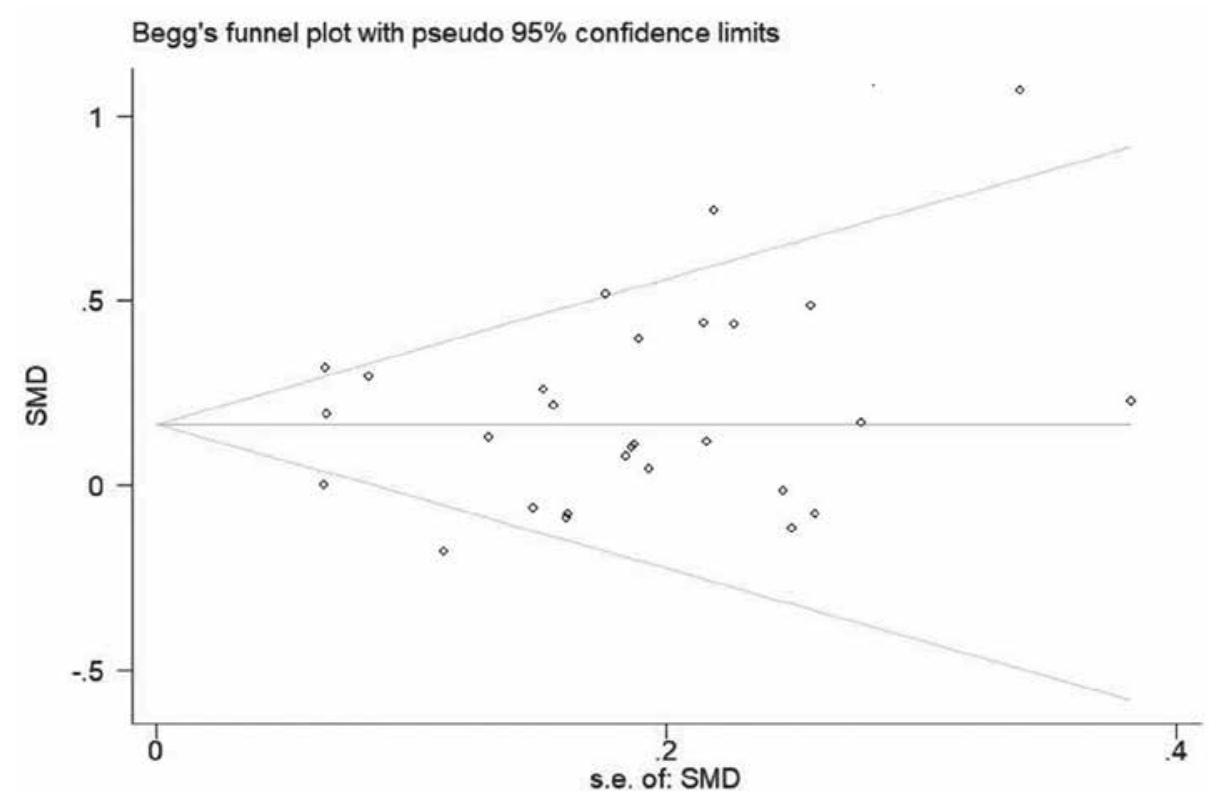




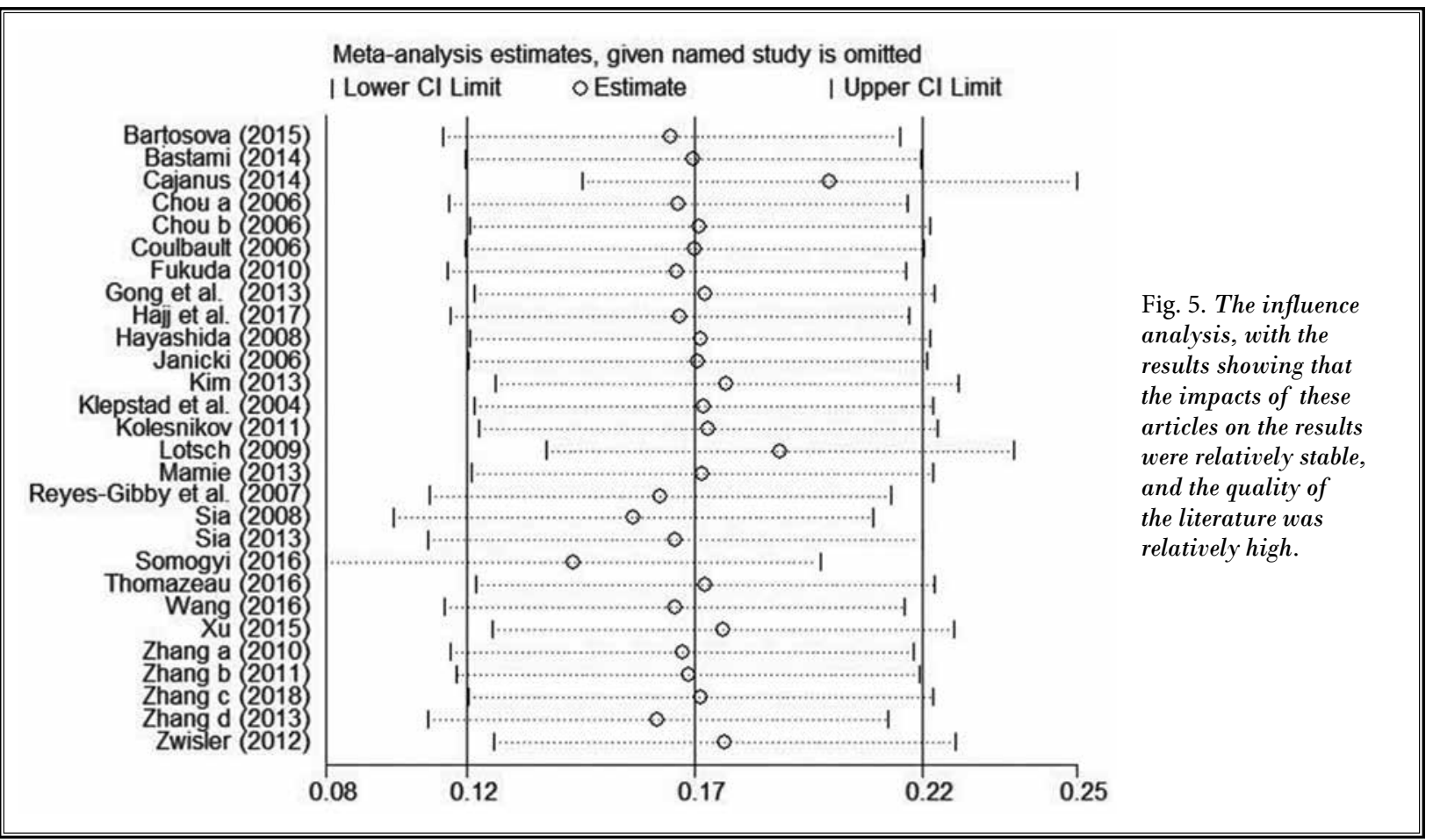

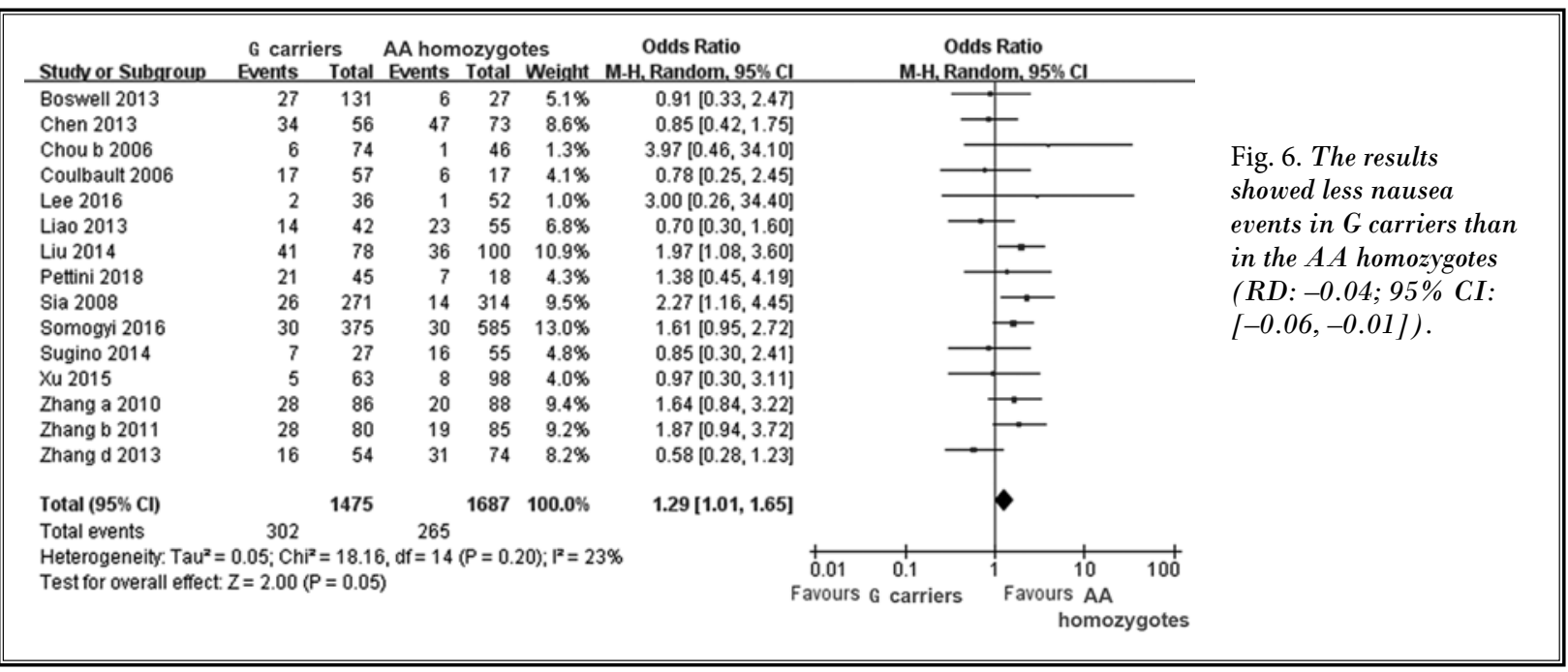

sequencing and bioengineering, it has been possible to prevent and treat diseases through genetic testing. Individual differences make pain treatment very difficult to manage. The research progress on pain-related genes has led to new directions in pain management. Supported by a large amount of literature, and based on our results of meta-analysis, OPRM1 A118G genetic variation has a great influence on the sensitivity of individuals to pain. Based on the type of gene mutation, clinicians may be able to individualize pain treatment to achieve better effects.

\section{Conclusions}

Our meta-analysis also had some limitations. Some other factors including nongenetic ones such as ages, gender, race, and genetic factors like gene-to-gene interaction may also influence the requirement of opioids. Also, only one of the articles included in our 
Pain Physician: July/August 2019: 22:331-340

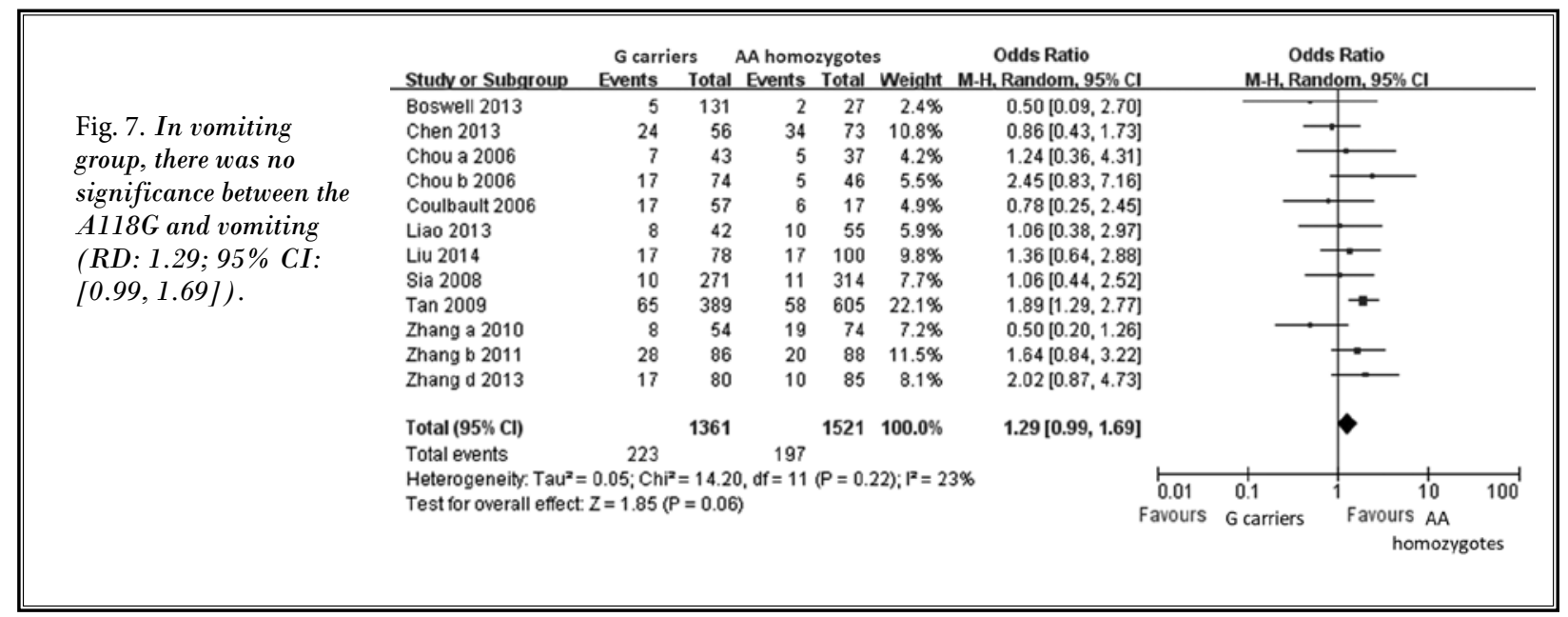

analysis had pain settings other than postoperative pain and cancer pain.

\section{Acknowledgments}

The authors would like to thank to Professor Chu and Professor Liang for the instructions on this meta-analysis.

\section{References}

1. Mercadante S, Bruera E. Opioid switching: A systematic and critical review. Cancer Treatment Rev 2006; 32:304-315.

2. Lotsch J, Skarke C, Liefhold J, Geisslinger G. Genetic predictors of the clinical response to opioid analgesics: Clinical utility and future perspectives. Clin Pharmacokinet 2004; 43:983-1013.

3. Romberg R, Olofsen E, Sarton E, den Hartigh J, Taschner PE, Dahan A. Pharmacokinetic-pharmacodynamic modeling of morphine-6-glucuronide-induced analgesia in healthy volunteers: Absence of sex differences. Anesthesiology 2004; 100:120-133.

4. Ikeda K, Ide S, Han W, Hayashida M, UhI GR, Sora I. How individual sensitivity to opiates can be predicted by gene analyses. Trends Pharmacol Sci 2005; 26:311-317.

5. Xu Y, Carr LG. Transcriptional regulation of the human mu opioid receptor (hMOR) gene: Evidence of positive and negative cis-acting elements in the proximal promoter and presence of a distal promoter. DNA Cell Biol 2001; 20:391-402.
6. Lotsch J, Zimmermann M, Darimont J, Marx C, Dudziak R, Skarke C, Geisslinger $G$. Does the A118G polymorphism at the mu-opioid receptor gene protect against morphine-6-glucuronide toxicity? Anesthesiology 2002; 97:814-819.

7. Klepstad P, Rakvag TT, Kaasa S, Holthe M, Dale O, Borchgrevink PC, Baar C, Vikan T, Krokan HE, Skorpen F. The 118 $A>G$ polymorphism in the human muopioid receptor gene may increase morphine requirements in patients with pain caused by malignant disease. Acta Anaesthesiol Scand 2004; 48:1232-1239.

8. Fukuda K, Hayashida M, Ide S, Saita N, Kokita Y, Kasai S, Nishizawa D, Ogai Y, Hasegawa J, Nagashima M, Tagami M, Komatsu H, Sora I, Koga H, Kaneko Y, Ikeda K. Association between OPRM gene polymorphisms and fentanyl sensitivity in patients undergoing painful cosmetic surgery. Pain 2009; 147:194-201.

9. Hajj A, Halepian L, Osta NE, Chahine G, Kattan J, Rabbaa Khabbaz L. OPRMı c.118A $>\mathrm{G}$ polymorphism and duration of morphine treatment associated with morphine doses and quality-of-life in palliative cancer pain settings. Int J Mol Sci 2017; 18:669.

10. Mague SD, Isiegas C, Huang P, LiuChen LY, Lerman C, Blendy JA. Mouse model of OPRM1 (A $118 \mathrm{G}$ ) polymorphism has sex-specific effects on drugmediated behavior. Proc Natl Acad Sci U S A 2009; 106:10847-10852.

11. Reyes-Gibby CC, Shete S, Rakvag T, Bhat SV, Skorpen F, Bruera E, Kaasa S, Klepstad P. Exploring joint effects of genes and the clinical efficacy of morphine for cancer pain: OPRM 1 and COMT gene. Pain 2007; 130:25-30.

12. Klepstad P, Fladvad T, Skorpen F, Bjordal K, Caraceni A, Dale O, Davies A, Kloke $M$, Lundstrom S, Maltoni M, Radbruch L, Sabatowski R, Sigurdardottir V, Strasser F, Fayers PM, Kaasa S. Influence from genetic variability on opioid use for cancer pain: A European genetic association study of 2294 cancer pain patients. Pain 2011; 152:1139-1145.

13. Higgins JP, Thompson SG. Quantifying heterogeneity in a meta-analysis. Stat Med 2002; 21:1539-1558.

14. Zhang W, Chang YZ, Kan QC, Zhang LR, 
Lu H, Chu QJ, Wang ZY, Li ZS, Zhang J. Association of human micro-opioid receptor gene polymorphism Al18G with fentanyl analgesia consumption in Chinese gynaecological patients. Anaesthesia 2010; 65:130-135.

15. Sia AT, Lim Y, Lim EC, Ocampo CE, Lim WY, Cheong P, Tan EC. Influence of muopioid receptor variant on morphine use and self-rated pain following abdominal hysterectomy. J Pain 2013; 14:1045-1052.

16. Khalil H, Sereika SM, Dai F, Alexander S, Conley Y, Gruen G, Meng L, Siska P, Tarkin I, Henker R. OPRM 1 and COMT gene-gene interaction is associated with postoperative pain and opioid consumption after orthopedic trauma. Biol Res Nurs 2017; 19:170-179.

17. Solak O, Erdogan MO, Yildiz H, Ulasli AM, Yaman F, Terzi ES, Ulu S, Dundar $U$, Solak M. Assessment of opioid receptor mu1 gene Al18G polymorphism and its association with pain intensity in patients with fibromyalgia. Rheumatol Int 2014; 34:1257-1261.

18. Almenara S, Planelles B, López-Gil $S$, López-Gil V, Inda MM, Nuñez A, Morales $D$, Margarit $C$, Peiró AM. Pharmacogenetics of pain and analgesia of tapentadol in chronic pain. Basic Clin Pharmacol Toxicol 2016; 119:33.

19. Gong XD, Wang JY, Liu F, Yuan HH, Zhang WY, Guo YH, Jiang B. Gene polymorphisms of OPRM1 Al18G and $A B C B 1 C_{3435} T$ may influence opioid requirements in Chinese patients with cancer pain. Asian Pac J Cancer Prev 2013; 14:2937-2943.

20. Cieslinska A, Sienkiewicz-Szlapka E, Kostyra E, Fiedorowicz E, Snarska J, Wronski $\mathrm{K}$, Tenderenda $\mathrm{M}$, Jarmolowska $\mathrm{B}$, Matysiewicz M. $\mu$-Opioid receptor gene (OPRM1) polymorphism in patients with breast cancer. Tumour Biol 2015; 36:4655-466o.

21. De Capraris A, Cinnella G, Marolla A, Salatto P, Da Lima S, Vetuschi P, Consoletti L, Gesualdo L, Dambrosio M. Micro opioid receptor A118G polymorphism and post-operative pain: Opioids' effects on heterozygous patients. Int J Immunopathol Pharmacol 2011; 24:993-1004.

22. Hwang IC, Park JY, Myung SK, Ahn HY, Fukuda K, Liao Q. OPRMı Aı18G gene variant and postoperative opioid requirement: A systematic review and meta-analysis. Anesthesiology 2014; 121:825-834.

23. Zhang W, Yuan JJ, Kan QC, Zhang LR, Chang YZ, Wang ZY. Study of the OPRM1 Al18G genetic polymorphism associated with postoperative nausea and vomiting induced by fentanyl intravenous analgesia. Minerva Anestesio 2011; 77:33-39.

24. Sugino $S$, Hayase $T$, Higuchi $M$, Saito $\mathrm{K}$, Moriya $\mathrm{H}$, Kumeta $\mathrm{Y}$, Kurosawa $\mathrm{N}$, Namiki A, Janicki PK. Association of mu-opioid receptor gene (OPRMI) haplotypes with postoperative nausea and vomiting. Exp Brain Res 2014; 232:2627-2635

25. Bartosova O, Polanecky O, Perlik F, Adamek S, Slanar O. OPRM 1 and ABCB 1 polymorphisms and their effect on postoperative pain relief with piritramide. Physiol Res 2015; 64(Suppl 4):S521-527.

26. Bastami S, Gupta A, Zackrisson AL, Ahlner J, Osman A, Uppugunduri S. Influence of $U_{G_{2}} B_{7}, O_{1} M_{1}$ and $A B C B 1$ gene polymorphisms on postoperative morphine consumption. Basic Clin Pharmacol Toxicol 2014; 115:423-431.

27. Cajanus K, Kaunisto MA, Tallgren M, Jokela R, Kalso E. How much oxycodone is needed for adequate analgesia after breast cancer surgery: Effect of the OPRM1 $118 \mathrm{~A}>\mathrm{G}$ polymorphism. J Pain 2014; 15:1248-1256.

28. Chou WY, Wang $\mathrm{CH}$, Liu PH, Liu CC, Tseng CC, Jawan B. Human opioid receptor A118G polymorphism affects intravenous patient-controlled analgesia morphine consumption after total abdominal hysterectomy. Anesthesiology 2006; 105:334-337.

29. Chou WY, Yang LC, Lu HF, Ko JY, Wang $\mathrm{CH}$, Lin SH, Lee TH, Concejero A, Hsu C). Association of mu-opioid receptor gene polymorphism (A118G) with variations in morphine consumption for analgesia after total knee arthroplasty. Acta Anaesthesiol Scand 2006; 50:787-792.

30. Coulbault L, Beaussier M, Verstuyft C, Weickmans $H$, Dubert L, Trégouet $D$, Descot C, Parc Y, Lienhart A, Jaillon $P$, Becquemont L. Environmental and genetic factors associated with morphine response in the postoperative period. Clin Pharmacol Ther 2006; 79:316-324.

31. Fukuda K, Hayashida M, Ikeda K, Koukita $Y$, Ichinohe T, Kaneko Y. Diversity of opioid requirements for postoperative pain control following oral surgery-Is it affected by polymorphism of the mu-opioid receptor? Anesth Prog 2010; 57:145-149.

32. Hayashida $M$, Nagashima $M$, Satoh $Y$, Katoh R, Tagami M, Ide S, Kasai $S$, Nishizawa D, Ogai Y, Hasegawa J, Komatsu $\mathrm{H}$, Sora I, Fukuda K, Koga H, Hanaoka K, Ikeda K. Analgesic requirements after major abdominal surgery are associated with OPRM 1 gene polymorphism genotype and haplotype. Pharmacogenomics 2008; 9:1605-1616.

33. Janicki PK, Schuler G, Francis D, Bohr A, Gordin $\mathrm{V}$, Jarzembowski T, Ruiz-Velasco $V$, Mets $B$. A genetic association study of the functional A118G polymorphism of the human mu-opioid receptor gene in patients with acute and chronic pain. Anesth Analg 2006; 103:1011-1017.

34. Kim KM, Kim HS, Lim SH, Cheong SH, Choi EJ, Kang H, Choi HR, Jeon JW, Yon $J H$, Oh M, Shin JG. Effects of genetic polymorphisms of $\mathrm{OPRM} 1, A B C B 1$, $\mathrm{CYP}_{3} \mathrm{~A}_{4} / 5$ on postoperative fentanyl consumption in Korean gynecologic patients. Int J Clin Pharmacol Ther 2013; 51:383-392.

35. Kolesnikov Y, Gabovits B, Levin A, Voiko E, Veske A. Combined catechol-O-methyltransferase and mu-opioid receptor gene polymorphisms affect morphine postoperative analgesia and central side effects. Anesth Analg 2011; 112:448-453.

36. Lotsch J, von Hentig N, Freynhagen R, Griessinger N, Zimmermann M, Doehring $A$, Rohrbacher $M$, Sittl R, Geisslinger G. Cross-sectional analysis of the influence of currently known pharmacogenetic modulators on opioid therapy in outpatient pain centers. Pharmacogenet Genomics 2009; 19:429-436.

37. Manini AF, Jacobs MM, Vlahov D, Hurd YL. Opioid receptor polymorphism A 118 G associated with clinical severity in a drug overdose population. J Med Toxicol 2013; 9:148-154.

38. Sia AT, Lim Y, Lim EC, Goh RW, Law HY, Landau R, Teo YY, Tan EC. A118G single nucleotide polymorphism of human mu-opioid receptor gene influences pain perception and patient-controlled intravenous morphine consumption after intrathecal morphine for postcesarean analgesia. Anesthesiology 2008; 109:520-526.

39. Somogyi AA, Sia AT, Tan EC, Coller JK, Hutchinson MR, Barratt DT. Ethnicitydependent influence of innate immune genetic markers on morphine PCA requirements and adverse effects in postoperative pain. Pain 2016; 157:2458-2466.

40. Thomazeau J, Rouquette A, Martinez V, Rabuel C, Prince N, Laplanche JL, Nizard R, Bergmann JF, Perrot S, Lloret-Linares $C$. Acute pain factors predictive of post-operative pain and opioid requirement in multimodal analgesia following knee replacement. Eur J Pain 2016; 20:822-832. 
41. Wang Y, Tan Z, Wu L, Hu C, Yang J, Wen $Y$, Li Z, Liu J. Role of OPRM1, ABCB1 and $\mathrm{CYP}_{3} \mathrm{~A}$ genetic polymorphisms on sufentanil treatment of postoperative cancer patients in China. Int J Clin Exp Med 2016; 9:13250-13258.

42. Xu GH, Gao M, Sheng QY, Liu XS, Gu EW. Opioid receptor Al18G polymorphism does not affect the consumption of sufentanil and ropivacaine by patientcontrolled epidural analgesia after cesarean section. Ther Drug Monit 2015; 37:53-57.

43. Sistonen J, Madadi P, Ross CJ, Yazdanpanah M, Lee JW, Landsmeer MLA, Nauta M, Carleton BC, Koren G, Hayden MR. Prediction of codeine toxicity in infants and their mothers using a novel combination of maternal genetic markers. Clin Pharmacol Ther 2012; 91:692-699.

44. Zhang F, Liao Q, Li L, Wang SY, Hu R, Tang YZ, Ouyang W. The correlation between post-operative fentanyl requirements and mu-opioid receptor gene A118G polymorphism in patients undergoing radical gastrectomy. Exp Ther Med 2013; 5:1147-1152.

45. Zhang J, Zhang L, Zhao X, Shen S, Luo $\mathrm{X}$, Zhang $\mathrm{Y}$. Association between MDRI/ $\mathrm{CYP}_{3} \mathrm{~A}_{4} / \mathrm{OPRM}$ gene polymorphisms and the post-caesarean fentanyl analgesic effect on Chinese women. Gene 2018; 661:78-84.

46. Zwisler ST, Enggaard TP, Mikkelsen S,
Verstuyft C, Becquemont L, Sindrup SH, Brosen K. Lack of association of OPRM 1 and $A B C B 1$ single-nucleotide polymorphisms to oxycodone response in postoperative pain. J Clin Pharmacol 2012; 52:234-242.

47. Boswell MV, Stauble ME, Loyd GE, Langman L, Ramey-Hartung B, Baumgartner RN, Tucker WW, Jortani SA. The role of hydromorphone and OPRM 1 in postoperative pain relief with hydrocodone. Pain Physician 2013; 16:E227-E235.

48. Chen LK, Chen SS, Huang $\mathrm{CH}$, Yang HJ, Lin CJ, Chien KL, Fan SZ. Polymorphism of mu-opioid receptor gene (OPRM1:c.118A>G) might not protect against or enhance morphine-induced nausea or vomiting. Pain Res Treat 2013; 2013:259306.

49. Lee MG, Kim HJ, Lee KH, Choi YS. The influence of genotype polymorphism on morphine analgesic effect for postoperative pain in children. Korean J Pain 2016; 29:34-39.

50. Liao Q, Chen DJ, Zhang F, Li L, Hu R, Tang YZ, Ou-Yang W, Huang D. Effect of $\mathrm{CYP}_{3} \mathrm{~A}_{4}{ }_{1} 8 \mathrm{~B}$ polymorphisms and interactions with OPRM $A_{11} 8 \mathrm{G}$ on postoperative fentanyl requirements in patients undergoing radical gastrectomy. Mol Med Rep 2013; 7:901-908.

51. Liu J, Hu D, Jiang Y, Xi H, Li W. Association between single nucleotide polymorphisms in the OPRMı gene and in- traoperative remifentanil consumption in northern Chinese women. Pharmacology 2014; 94:273-279.

52. Pettini E, Micaglio M, Bitossi U, De Gaudio AR, Degl'Innocenti DR, Tofani L, Limatola V, Adembri C, Di Filippo A. Influence of OPRM1 polymorphism on postoperative pain after intrathecal morphine administration in Italian patients undergoing elective cesarean section. Clin J Pain 2018; 34:178-181.

53. Zhang S, Li S, Tan X. [Human $\mu$-opioid receptor Al18G polymorphism affects epidural patient-controlled analgesia with fentanyl]. Nan Fang Yi Ke Da Xue Xue Bao 2013; 33:309-311.

54. Tan EC, Lim EC, Teo YY, Lim Y, Law HY, Sia AT. Ethnicity and OPRM variant independently predict pain perception and patient-controlled analgesia usage for post-operative pain. Mol Pain 2009; $5: 32$.

55. Walter C, Lotsch J. Meta-analysis of the relevance of the OPRM $1118 \mathrm{~A}>\mathrm{G}$ genetic variant for pain treatment. Pain 2009; 146:270-275.

56. Ren $Z Y, X u X Q$, Bao YP, He J, Shi L, Deng JH, Gao XJ, Tang HL, Wang YM, Lu L. The impact of genetic variation on sensitivity to opioid analgesics in patients with postoperative pain: A systematic review and meta-analysis. Pain Physician 2015; 18:131-152. 